\title{
Book Review: \\ Dirty Words and Filthy Pictures: Film and the First Amendment
}

\author{
Geltzer, Jeremy \\ Austin: University of Texas Press, 2016. \\ Ben Strassfeld ${ }^{1}$ \\ University of Michigan \\ bstrass@ umich.edu
}

The history of media censorship is told in large part through technical legal texts that at times seem to be written in a foreign language. For a film and media scholar, the ordeal of wading through these texts can leave one with the decided urge to go back to law school, if one only had a spare two years and \$100,000 lying around. Thankfully, Jeremy Geltzer's new book Dirty Words and Filthy Pictures: Film and the First Amendment provides a comprehensive and comprehensible look at the relationship between film and legal censorship. Drawing on his background as an attorney, Geltzer is able to cut through the legal-ese that can be so daunting, making legible a history that is often dry and opaque.

Geltzer's book is impressive in its scope, covering over a century of the legal history of film and media censorship. He begins in the early days of cinema, when boxing pictures and films like The Kiss (1896) led to scandal and censorship for the

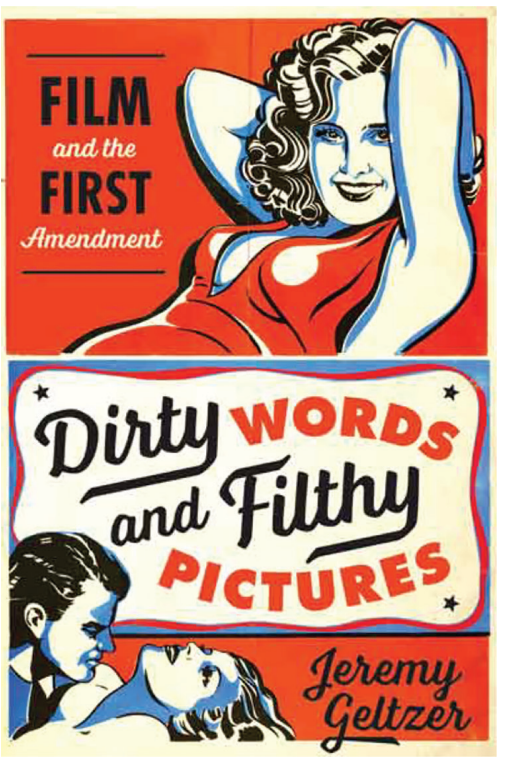
new medium. The book proceeds forward in time, cataloging court cases surrounding films both celebrated and obscure. Movies both high and lowbrow receive attention here; the boundary-pushing exploitation films of Russ Meyer are given equal footing with the edgy features of Otto Preminger.

If the book casts a set of heroes, however, it is comprised less of filmmakers charting new territory in their films and more of lawyers defending them. Geltzer provides attorneys like Ephraim London, who crafted new and innovative legal arguments, with as much attention as the filmmakers whose work the lawyers defended. Likewise, judges - both those in favor and opposed to extending First Amendment protections to cinema - are key players in this book. 
Some of this history will be familiar to media studies scholars. It would be hard to add much to the mountain of scholarship generated by the "Mutual Case," the 1915 case that denied movies First Amendment protections, for instance. Still, if Geltzer does not provide many new insights in this particular instance, he still gives a strong and succinct reading of the legal implications of the case, placing it within the context of other key judicial rulings of the era. Likewise, his reading of the 1952 "Miracle Decision," which finally granted movies First Amendment protection, while not providing any major new revelations, nevertheless is a compelling analysis of the monumental legal case.

Where Geltzer excels is in his treatment of less-heralded court decisions, tracing the censorship histories of individual films and filmmakers across various cities and states. As Geltzer moves vertically across a century of censorship history, he brings attention to these overlooked pieces of history that give the book an impressive depth and provide a wide horizontal view of legal cases across the United States. Some areas famous for their censorial activity loom large-Kansas and New York are well represented here-but states such as Maryland, Pennsylvania, and Ohio, as well as countless cities both small and large, are also given extensive coverage. The book is focused on the United States, with international contexts only entering his analysis insofar as foreign films became the subject of legal battles within the United States.

The book's full title, promising a focus on "Film and the First Amendment," actually sells it short, as Geltzer extensively discusses other amendments beyond the first. Historians have only recently begun to fully grapple with the way that laws operating outside the boundaries of the First Amendment have significantly affected the regulation of media. As First Amendment protections were expanded to include moving images, municipalities increasingly relied on alternate modes of regulation, ones that could (seemingly) bypass arguments over free speech by instead emphasizing nuisance or zoning laws. Geltzer deftly elucidates the legal battles over these regulatory methods, showing how efforts to censor media, rather than disappearing after the Miracle case, only got slyer and more complex.

Perhaps unsurprisingly, given the author's background, the book is at its weakest when the story drifts too far from the courtroom. Geltzer relies primarily on court decisions for his sources, which benefits the legal analysis at the heart of the book. Once censorship moves into extralegal territory, however, the book feels somewhat thin. This is an issue particularly when it comes to the self-regulatory efforts of Hollywood, highlighted by the Production Code and its eventual replacement, the ratings system. The code and ratings system were designed to keep films and filmmakers out of courtrooms altogether, and so the book winds up relying on generalities when discussing these systems of self-regulation.

Likewise, the book's regional heterogeneity has drawbacks. The book gives short shrift to the type of local cultural and political contexts that might help readers understand the origins of local cases of censorship. While Geltzer does focus on key local figures - be they judges or police officers - too often what is lost is the political contexts from which these figures emerged. We are not provided with a deep analysis of how Progressive Era politics in Chicago affected censorship practices during the early twentieth century, for example. The relationship between Detroit's urban crisis in the early 1970s and the city's adoption of an influential zoning law dispersing adult movie theaters is also not adequately explored. 
These issues hardly detract from the book as a whole though. For scholars interested in the history of film censorship, Dirty Words and Filthy Pictures offers a useful source of legal history, illuminating a story that often seems all too baffling in its complexity.

${ }^{1}$ Ben Strassfeld is a PhD candidate in the Department of Screen Arts and Cultures at the University of Michigan. He is in the process of completing his dissertation, looking at the history of anti-pornography politics and media censorship in Detroit during the 1950s, 1960s, and 1970s. 
